\title{
Highly efficient silver-assisted reduction of graphene oxide dispersions at room temperature: mechanism, and catalytic and electrochemical performance of the resulting hybrids
}

M. Ayán-Varela ${ }^{\mathrm{a}}$, M.J. Fernández-Merino a , J.I. Paredes ${ }^{\mathrm{a}}$, S. Villar-Rodil ${ }^{\mathrm{a}}$, C. Fernández-

\author{
Sánchez $^{\mathrm{b}}$, L. Guardia ${ }^{\mathrm{a}}$, A. Martínez-Alonso ${ }^{\mathrm{a}}$, J.M.D. Tascón ${ }^{\mathrm{a}}$ \\ ${ }^{a}$ Instituto Nacional del Carbón, INCAR-CSIC, Apartado 73, 33080 Oviedo, Spain \\ ${ }^{\mathrm{b}}$ Instituto de Microelectrónica de Barcelona, IMB-CNM (CSIC), Campus UAB, 08193
}

Bellaterra, Barcelona, Spain

\begin{abstract}
Metal-assisted reduction of graphene oxide (GO) has recently emerged as a fast, efficient and room-temperature method towards the preparation of chemically derived graphene, but according to the mechanisms of reduction that have been proposed, not all relevant metals (e.g., Ag) should be a priori effective for this purpose. Here, we show that aqueous GO dispersions can be very efficiently reduced at room temperature with $\mathrm{NaBH}_{4}$ using $\mathrm{Ag}$ nanoparticles (Ag NPs) as catalysts, either generated in situ from appropriate precursors $\left(\mathrm{AgNO}_{3}\right)$ or added to the dispersions as pre-formed objects. We propose and investigate a reduction mechanism that involves the charging of the $\mathrm{Ag}$ NPs with excess electrons obtained from the oxidation of a product of the spontaneous hydrolysis of $\mathrm{NaBH}_{4}$ in the aqueous medium. These excess electrons are then transferred to the GO sheets, triggering their reduction. The catalytic and electrochemical performance of the reduced GO-Ag NP hybrids that result from this process has also been examined. In particular, the hybrids were seen to exhibit a very high catalytic activity in the reduction of 4-nitrophenol to 4-aminophenol as a model reaction, and were also effective towards the electrochemical reduction of $\mathrm{H}_{2} \mathrm{O}_{2}$.
\end{abstract}




\section{Introduction}

As a novel two-dimensional material that exhibits a host of outstanding physical properties (electronic, mechanical, thermal, optical, etc), ${ }^{1,2}$ graphene is being intensively investigated at present for its potential use in many relevant technological applications, ${ }^{3}$ which span the fields of electronics, ${ }^{4}$ photonics, ${ }^{5}$ chemical sensing and biosensing, ${ }^{6}$ energy conversion and storage, ${ }^{7}$ composite materials, ${ }^{8}$ catalysis ${ }^{9}$ and biomedicine. ${ }^{10}$ Such a broad spectrum of prospective uses requires the availability of large quantities of graphene and graphene derivatives with very different specifications in terms of, e.g., lateral size and layer number, presence of defects, chemical doping and functionalization, or liquid-phase processability. In the absence of a universal and truly versatile method that can deliver graphene and its derivatives with any on-demand characteristics, the research community has focused over the last years on the development of several top-down and bottom-up production approaches that are best suited to certain areas of application. ${ }^{3,11}$

One of such approaches is the well-known graphite oxide route, which is based on the exfoliation of this highly oxygenated derivative of graphite to give individual, single-layer sheets [graphene oxide (GO) sheets] and its subsequent reduction to remove the oxygen functional groups that heavily decorate the carbon skeleton of GO, yielding what is referred to as reduced graphene oxide (RGO). ${ }^{12-14}$ The latter step is particularly important to attain a final product that ideally should resemble pristine graphene as much as can be possible (in practice, residual oxygen groups and defects are almost invariably present in RGO). For this reason, a lot of effort has been devoted to the development of different methodologies for the reduction of GO, including those of chemical, thermal, solvothermal, photothermal, photocatalytic and electrochemical 
nature. ${ }^{15,16}$ Each of these methodologies has its own advantages and drawbacks and leads to RGO products with specific characteristics.

From a perspective of scalable and cost-effective production of RGO, it would be beneficial to make use of a reduction method that was fast, highly efficient, easy to implement, non- or low-polluting, and did not require an external energy input (i.e., it could be carried out at room temperature). Most of the known reduction approaches do not satisfy several of these conditions. By contrast, reduction of GO assisted by metals has emerged in very recent years as an attractive alternative that could better comply with most, if not all, of the aforementioned requirements. Metal-assisted reduction can be accomplished through either one of two clearly distinct processes. One of these processes exploits the ability of non-noble metals, such as $\mathrm{Al},{ }^{17,18} \mathrm{Fe},{ }^{19} \mathrm{Zn},{ }^{20-24} \mathrm{Ni}^{25}$ or $\mathrm{Mg},{ }^{26}$ to act as reducing agents. The reaction is typically (although not exclusively) conducted in acidic medium to favor the formation of hydrogen atoms that can readily abstract oxygen groups from the GO sheets. ${ }^{17-19,20,22,24-27}$ The other process is based on the use of a noble, e.g. $\mathrm{Pd},{ }^{28} \mathrm{Pt}^{29,30}$ or $\mathrm{Au},{ }^{31}$ or a non-noble (e.g., $\left.\mathrm{Cu}\right)^{32}$ metal as a catalyst rather than a reactant. In this case $\mathrm{H}_{2}$ or $\mathrm{NaBH}_{4}$ are mostly employed as reductants, which are either dissociated $\left(\mathrm{H}_{2}\right)^{28-30}$ or hydrolyzed $\left(\mathrm{NaBH}_{4}\right)^{31,32}$ on the metal surface to yield hydrogen atoms that subsequently reach the GO sheets through spillover.

Although some metals have proved their efficacy towards the catalyzed reduction of GO, we would expect others to be a priori ineffective for such a purpose. This is specifically the case of $\mathrm{Ag}$, which is known to be essentially inert as a catalyst for both the dissociation of $\mathrm{H}_{2}{ }^{33-35}$ and the hydrolysis of $\mathrm{NaBH}_{4} \cdot{ }^{36,37}$ In fact, alloys containing this noble metal have been proposed as catalysts that can prevent the problem of hydrolysis in direct borohydride fuel cells. ${ }^{36}$ Although there are two previous instances 
in the literature on reduction of GO catalyzed by $\mathrm{Ag}$, one deals with photocatalysis, ${ }^{38}$ and the other requires heating during a long time to reduce GO to a limited extent. ${ }^{39}$ However, we have found that Ag nanoparticles (Ag NPs) are able to catalyze a highly efficient reduction of aqueous $\mathrm{GO}$ dispersions with $\mathrm{NaBH}_{4}$ at room temperature, which we report here. As will be shown below, this catalytic reduction can be carried out in a matter of minutes using Ag NPs either synthesized in situ or previously formed, and the extent of reduction achieved is larger than that typically attained when $\mathrm{NaBH}_{4}$ is used alone at higher temperatures $\left(70-95^{\circ} \mathrm{C}\right)$. To rationalize such results, we propose and discuss a reduction mechanism that involves the transfer of electrons from $\mathrm{BH}_{3} \mathrm{OH}^{-}$ species derived from $\mathrm{BH}_{4}{ }^{-}$to the GO sheets via the Ag NPs. This simple, one-step process directly yields RGO-Ag NP hybrids, which are interesting for different applications. ${ }^{38-40}$ In this context, we demonstrate the application potential of the RGOAg NP hybrids obtained by this fast and effective approach by investigating (1) their catalytic activity towards the reduction of 4-nitrophenol (4-NP) to 4-aminophenol (4AP) as a model reaction, and (2) their use as an electrode for the electrochemical detection of $\mathrm{H}_{2} \mathrm{O}_{2}$.

\section{Experimental}

\subsection{Room-temperature reduction of GO assisted by silver}

Graphene oxide in aqueous dispersion was obtained from graphite as follows. First, graphite oxide was prepared by the Hummers method starting from natural graphite powder (Sigma Aldrich) and using $\mathrm{NaNO}_{3}, \mathrm{H}_{2} \mathrm{SO}_{4}$ and $\mathrm{KMnO}_{4}$ as reagents. The details of the oxidation procedure can be found elsewhere. ${ }^{41}$ The oxidized product was purified by first rinsing with $1 \% \mathrm{HCl}$ solution and then copiously washing with Milli-Q water to yield a thick graphite oxide slurry. This slurry was dispersed in water, sonicated in an 
ultrasound bath cleaner (J.P. Selecta Ultrasons apparatus) for $4 \mathrm{~h}$, centrifuged (Eppendorf 5424 microcentrifuge) at $20000 \mathrm{~g}$ for $10 \mathrm{~min}$, and the top $\sim 75 \%$ of the supernatant volume, which was the as-prepared GO dispersion, collected for use in the subsequent experiments. The concentration of the suspension was determined by UVvis absorption spectroscopy using a previously reported procedure. ${ }^{42}$

Although the effect of different experimental parameters on the Ag-assisted reduction of the GO sheets was investigated and will be discussed later, a typical optimized procedure was as follows: to a given volume of the as-prepared dispersion ( $\mathrm{pH} \sim 4.5,0.1 \mathrm{mg} \mathrm{mL}^{-1}$ ), we first added $\mathrm{AgNO}_{3}$ to reach a concentration of $0.5 \mathrm{mM}$ and then $\mathrm{NaBH}_{4}$ (to a concentration of $22.5 \mathrm{mM}$ ). The resulting mixture was left to stand undisturbed at room temperature. Immediately after addition of $\mathrm{NaBH}_{4}$, the dispersion turned dark green, indicative of the formation of Ag NPs, and after a few $(<5)$ minutes the color changed to opaque black (with a greenish tone), suggesting reduction of the GO sheets. To avoid precipitation of the resulting RGO-Ag NP hybrids, a certain amount of surfactant was added to the aqueous dispersions. As detailed below, several surfactants were tested, but optimal performance was found with sodium dodecylbenzene sulfonate (SDBS, at a concentration of $0.075 \%$ wt./vol.) and polyvinylpyrrolidone (PVP, $0.01 \%$ wt./vol), which conferred the hybrids long-term colloidal stability. Finally, to remove unwanted reaction products the dispersions were dialyzed using cellulose ester membranes (Spectra/Por® Float-A-Lyzer® G2, $10^{6}$ Da molecular weight cut-off, from Spectrum Laboratories) for one day.

\subsection{Characterization techniques}

The samples were characterized by UV-vis absorption spectroscopy, inductively coupled plasma-mass spectrometry (ICP-MS), X-ray photoelectron spectroscopy (XPS), 
scanning transmission electron microscopy (STEM), transmission electron microscopy (TEM) and electrochemical impedance spectroscopy (EIS). UV-vis absorption spectra were recorded in a double-beam He $\lambda$ ios $\alpha$ spectrophotometer (Thermo Spectronic). ICP-MS analyses were performed with a 7500ce (Agilent) instrument equipped with an octopole collision/reaction cell to destroy interfering ions. Prior to analysis, the RGOAg NP hybrids were subjected to microwave-assisted acid digestion. XPS measurements were carried out on a SPECS system under a pressure of $10^{-7} \mathrm{~Pa}$ with a monochromatic $\mathrm{Al} \mathrm{K} \mathrm{K}_{\alpha} \mathrm{X}$-ray source operated at $14.00 \mathrm{kV}$ and $100 \mathrm{~W}$. Specimens for XPS analysis were prepared by drop-casting the aqueous dispersions onto a metallic sample-holder pre-heated at $\sim 50-60^{\circ} \mathrm{C}$, which was allowed to dry. STEM images were acquired on a Quanta FEG 650 system (FEI Company) operated at $30 \mathrm{kV}$, whereas TEM imaging was performed with a JEOL 2000 EX-II instrument operated at $160 \mathrm{kV}$. Specimens for both STEM and TEM were prepared by mixing equal volumes of the aqueous suspension of the sample and ethanol. Then, $40 \mu \mathrm{L}$ of the resulting mixture were drop-cast onto a copper grid (200 square mesh) covered with a carbon film (Electron Microscopy Sciences) and allowed to dry. EIS studies were carried out using a three electrode configuration including a glassy carbon working electrode $(\mathrm{GC}, \mathrm{CH}$ Instruments, Inc., USA), a Ag/ $\mathrm{AgCl}$ reference electrode and a Pt counter electrode (both from Metrohm AG, Switzerland), in a $0.1 \mathrm{M} \mathrm{KNO}_{3}$ solution containing $1 \mathrm{mM}$ ferrocyanide and $1 \mathrm{mM}$ ferricyanide electroactive species. The GC electrode was modified with GO and Ag NPs by casting a single $6 \mu \mathrm{L}$-drop of a mixed aqueous suspension containing $0.05 \mathrm{mg} \mathrm{mL}^{-1} \mathrm{GO}$ and $0.01 \mathrm{mg} \mathrm{mL}^{-1}$ pre-formed Ag NPs, which was then left to dry at room temperature. Impedance spectra in the form of Nyquist plots were recorded using an Autolab PGSTAT30 potentiostat equipped with a Fra module (EcoChemie, The Netherlands), controlled by Fra software version 4.3. 
Measurements were carried out in a frequency range of $10 \mathrm{kHz}$ to $10 \mathrm{~Hz}$ (10 point per decade), with an amplitude of $10 \mathrm{mV}$ and a DC potential of $+0.134 \mathrm{~V}$ (vs. $\mathrm{Ag} / \mathrm{AgCl}$ reference electrode), this being the half-wave potential of the ferrocyanide/ferricyanide redox pair. The Randles equivalent circuit was used to fit the impedance spectra and thus make an estimation of the charge transfer resistance $\left(\mathrm{R}_{\mathrm{ct}}\right)$. This electrical parameter describes the heterogeneous electron transfer of the electroactive species in solution taking place at the GC electrode solution interface. ${ }^{43}$

\subsection{Catalytic and electrochemical activity assays}

The catalytic activity of selected RGO-Ag NP hybrids was evaluated in a model reaction, namely, the reduction of $4-\mathrm{NP}$ to $4-\mathrm{AP}$ with $\mathrm{NaBH}_{4}$ at room temperature in aqueous medium. To this end, equal volumes of freshly prepared aqueous solutions of 4-NP (10 mM) and $\mathrm{NaBH}_{4}(6 \mathrm{M})$ were mixed and stirred vigorously. Then, $25 \mu \mathrm{L}$ of the resulting mixture were added to $2.08 \mathrm{~mL}$ of an aqueous dispersion of the $\mathrm{RGO}-\mathrm{Ag} \mathrm{NP}$ hybrid, so that the final concentration of Ag NPs in the reaction medium was adjusted to $\sim 1-2 \times 10^{10} \mathrm{~mL}^{-1}$. The progress of the reaction can be readily monitored with UV-vis

absorption spectroscopy as reported elsewhere, ${ }^{44}$ i.e. by recording the time evolution of the absorption peak characteristic of the 4-nitrophenoxide anion at $400 \mathrm{~nm}$.

Electrochemical studies were also carried out to assess the performance of the RGOAg NP hybrids as catalysts for the reduction of $\mathrm{H}_{2} \mathrm{O}_{2}$. Commercially available, screenprinted thick-film carbon electrodes (SPCEs), $4 \mathrm{~mm}$ in diameter and fabricated on an alumina substrate, together with carbon counter electrodes and silver pseudo-reference electrodes (DS 100 model), were purchased from DropSens S.L. (Spain) and used as received. Two $6 \mu \mathrm{L}$ drops of the hybrid dispersions were sequentially cast on the surface of a SPCE and allowed to dry at room temperature. Cyclic voltammograms 
were recorded with the resulting devices at room temperature in a $20 \mathrm{~mL}$ plastic cell filled with a $\mathrm{N}_{2}$-deareated $0.1 \mathrm{M}$ phosphate buffer solution containing $140 \mathrm{mM} \mathrm{NaCl}$ (PBS) and different concentrations of the target analyte under quiescent conditions. The devices were also calibrated by chronoamperometry at a set potential in PBS to which increasing concentrations of the target analyte were sequentially injected, under constant stirring conditions. These studies were performed using an Autolab PGSTAT30 potentiostat (EcoChemie, The Netherlands), controlled by Autolab GPES software version 4.3 .

\section{Results and discussion}

\subsection{Reduction of GO assisted by silver and formation of RGO-Ag NP hybrids}

Immediately after addition of appropriate amounts of $\mathrm{NaBH}_{4}$ to an aqueous solution containing $\mathrm{GO}$ sheets and $\mathrm{AgNO}_{3}$ at room temperature, the original color of the solution, which was yellow due to the GO sheets (see left vial in the inset to Fig. 1a), changed to dark green. This can be attributed to the formation of nanometer-sized Ag particles by reduction of the silver salt. Furthermore, within a few $(<5)$ minutes the color of the solution changed again, in this case to opaque black, although a greenish tone was preserved (inset to Fig. 1a, right vial), suggesting that reduction of the GO sheets took place. ${ }^{45}$ Evidence for both processes was obtained by UV-vis absorption spectroscopy (Fig. 1a). In the absence of $\mathrm{NaBH}_{4}$, the spectrum of a dispersion containing GO sheets and $\mathrm{AgNO}_{3}$ (orange plot) is dominated by an absorption peak located at $231 \mathrm{~nm}$ together with a shoulder at about $300 \mathrm{~nm}$, associated to $\pi \rightarrow \pi^{*}$ transitions of aromatic C-

$\mathrm{C}$ bonds and $\mathrm{n} \rightarrow \pi^{*}$ transitions in $\mathrm{C}=\mathrm{O}$ structures, respectively, in the GO sheets. ${ }^{46,47} \mathrm{~A}$ few minutes after addition of $\mathrm{NaBH}_{4}$, the absorption peak characteristic of $\mathrm{GO}$ appeared red-shifted to about $268 \mathrm{~nm}$ and a significant background absorbance was seen for the 
whole wavelength range above $268 \mathrm{~nm}$ (Fig. 1a, green plot). These features are clearly indicative of a very efficient reduction of the GO sheets. In fact, previous work has demonstrated that there is a good correlation between the extent of reduction achieved for GO and the magnitude of the red-shift for its characteristic absorption peak. ${ }^{48}$ In particular, reduction of $\mathrm{GO}$ with $\mathrm{NaBH}_{4}$ at $95{ }^{\circ} \mathrm{C}$ in the absence of silver is known to lead typically to absorption peaks red-shifted up to $266 \mathrm{~nm},{ }^{48}$ suggesting a noticeably lower degree of reduction than that reached with efficient reductants for GO, such as hydrazine and vitamin $\mathrm{C}$ or with naBH4 in the presence of silver. $\mathrm{NaBH}_{4}$ reduces efficiently aldehyde and ketone functionalities, while it is rarely useful for epoxide and carboxylic groups. ${ }^{27,49}$ Thus, its low efficiency in GO reduction can be put down to the fact that GO contains a great amount of functional groups of the type for which $\mathrm{NaBH}_{4}$ is not a good reductant. However, the room-temperature reduction with $\mathrm{NaBH}_{4}$ in the presence of silver investigated here leads to a noticeably higher degree of reduction than that attained at $95^{\circ} \mathrm{C}$ in the absence of silver (this point is confirmed below by XPS). Additionally, an intense band at $\sim 400 \mathrm{~nm}$ appears in the absorption spectrum of the $\mathrm{NaBH}_{4}$-treated dispersion, which is responsible for its greenish tone and can be ascribed to the surface plasmon resonance (SPR) band distinctive of metallic silver nanostructures, ${ }^{50}$ indicating that the $\mathrm{Ag}(\mathrm{I})$ species in $\mathrm{AgNO}_{3}$ have been reduced to $\operatorname{Ag}(0)$

Further evidence for the successful reduction of $\mathrm{GO}$ and $\mathrm{Ag}(\mathrm{I})$ was provided by means of XPS. Fig. 1b shows the high resolution C1s core level spectra for (i) the starting, unreduced GO sample (orange trace), (ii) a RGO sample prepared by reduction with $\mathrm{NaBH}_{4}$ at $95{ }^{\circ} \mathrm{C}$ in the absence of silver and shown here for comparison purposes (black trace), and (iii) GO treated with $\mathrm{NaBH}_{4}$ at room temperature in the presence of $\mathrm{AgNO}_{3}$ (green trace). The $\mathrm{C} 1 \mathrm{~s}$ band of the starting $\mathrm{GO}$ exhibits three components, 
located at 284.6, 286.6 and $287.9 \mathrm{eV}$, which can be ascribed to oxidation states 0,1 and 2 of the carbon atom, respectively, (i.e., graphitic $\mathrm{C}-\mathrm{C}, \mathrm{C}-\mathrm{O}$ and $\mathrm{C}=\mathrm{O}$ species, respectively). ${ }^{51}$ After treatment with $\mathrm{NaBH}_{4}$ in the presence of $\mathrm{AgNO}_{3}$, the relative intensity of the higher binding energy components associated to oxidation states other than 0 is seen to decrease drastically, consistent with an efficient reduction of the GO sheets. Furthermore, a $\pi \rightarrow \pi^{*}$ satellite band associated to well-developed electronic conjugation in carbon materials appears for this sample at $\sim 291 \mathrm{eV}$ (green spectrum in Fig. 1b). By contrast, for $\mathrm{GO}$ reduced with $\mathrm{NaBH}_{4}$ at $95{ }^{\circ} \mathrm{C}$ (black plot) a lower degree of reduction is apparent from the clearly visible, still relatively intense $\mathrm{C}-\mathrm{O}$ component. Such observations were further supported by the $\mathrm{O} / \mathrm{C}$ atomic ratios of the samples, as derived from their XPS survey spectra, which were 0.43 for unreduced GO, 0.26 for GO reduced with $\mathrm{NaBH}_{4}$ at $95{ }^{\circ} \mathrm{C}$ in the absence of $\mathrm{AgNO}_{3}$ and 0.12 for GO reduced with $\mathrm{NaBH}_{4}$ in the presence of $\mathrm{AgNO}_{3}$ at room temperature. The extent of reduction achieved for the latter is thus comparable to that attained with the most efficient chemical methods, which are typically carried out at higher temperatures (90-100 $\left.{ }^{\circ} \mathrm{C}\right) .{ }^{46,48}$

The Ag 3d high resolution spectrum shown in Fig. 1c is characteristic of GO dispersions treated with $\mathrm{NaBH}_{4}$ in the presence of $\mathrm{AgNO}_{3}$. It exhibits two symmetrical $\operatorname{Ag~} 3 \mathrm{~d}_{3 / 2}$ and $\mathrm{Ag} 3 \mathrm{~d}_{5 / 2}$ bands centered, respectively, at 374.4 and $368.4 \mathrm{eV}$, which can be ascribed to $\operatorname{Ag}(0)$, i.e. metallic silver. ${ }^{52}$ No sign of oxidized silver species, e.g. $\operatorname{Ag}(\mathrm{I})$, could be detected by XPS. The generation of metallic silver nanostructures revealed by UV-vis absorption spectroscopy and XPS was confirmed through direct observations by STEM and TEM (Fig. 2a and b, respectively). The RGO sheets were seen to be decorated by a number of black dots that did not form in the absence of $\mathrm{AgNO}_{3}$ (images not shown), so they can be attributed to Ag NPs. The Ag NPs were always found to be 
physically associated to the RGO sheets, i.e., no stand-alone nanoparticles were seen, indicating that RGO-Ag NP hybrids were indeed generated by the reduction process described here. The nanoparticles displayed more or less rounded shapes and their average size, estimated by TEM from a pool of about 900 individual objects, was $14 \pm 6$ $\mathrm{nm}$. Nanoparticle sizes ranged from $\sim 4$ to $45 \mathrm{~nm}$, although most of them $(\sim 65 \%)$ were between 8 and $14 \mathrm{~nm}$ (see Fig. 2c).

We infer that $\operatorname{Ag}(0)$ in the form of metallic nanoparticles, and not $\operatorname{Ag}(\mathrm{I})$ in $\mathrm{AgNO}_{3}$ itself, is the key element for the fast and effective reduction of the GO dispersions at room temperature observed here. In fact, reduction of GO could be equally attained when $\mathrm{AgNO}_{3}$ was replaced by comparable molar amounts of pre-formed Ag NPs of different sizes (e.g., 20 or $40 \mathrm{~nm}$ ). Fig. 3 shows the UV-vis absorption spectrum of an aqueous GO dispersion $\left(0.1 \mathrm{mg} \mathrm{mL}^{-1}\right)$ treated at room temperature with $\mathrm{NaBH}_{4}(22.5$ $\mathrm{mM})$ in the presence of pre-formed $\mathrm{Ag}$ NPs $\left(\sim 0.02 \mathrm{mg} \mathrm{mL}^{-1}, \sim 20 \mathrm{~nm}\right.$ in diameter). Again, the dispersion became opaque black in less than 5 minutes following addition of $\mathrm{NaBH}_{4}$ and exhibited, together with the SPR band of the Ag NPs at $389 \mathrm{~nm}$, an absorption peak at $268 \mathrm{~nm}$, indicating that the GO sheets were effectively reduced also in this case. The presence of silver was necessary to allow reduction of GO at room temperature: when $\mathrm{Ag}$ NPs or $\mathrm{AgNO}_{3}$ were excluded from the aqueous dispersion and only $\mathrm{NaBH}_{4}$ was present, no significant reduction of the sheets was observed even after several hours. Similarly, reduction did not take place with $\mathrm{Ag} \mathrm{NPs}$ or $\mathrm{AgNO}_{3}$ in the absence of $\mathrm{NaBH}_{4}$. In other words, the simultaneous presence of $\mathrm{NaBH}_{4}$ and $\mathrm{Ag}$ $\mathrm{NPs} / \mathrm{AgNO}_{3}$ is required for reduction. We also investigated the effect of the amount of $\mathrm{NaBH}_{4}$ and silver added to the dispersion on the reduction of the GO sheets. For example, for $0.1 \mathrm{mg} \mathrm{mL}{ }^{-1} \mathrm{GO}$ suspensions the optimal concentrations of $\mathrm{NaBH}_{4}$ and $\mathrm{AgNO}_{3}$ were determined to be 22.5 and $0.5 \mathrm{mM}$, respectively. Significantly lower 
concentrations of the former led to a limited reduction of the sheets, whereas higher concentrations did not afford further reduction but induced the prompt precipitation of the RGO product, probably as a result of the high ionic strength of the medium. Likewise, lower concentrations of $\mathrm{AgNO}_{3}$ (or pre-formed $\mathrm{Ag} \mathrm{NPs}$ ) tended to slow down the reduction rate of the sheets, while larger amounts did not have any significant effect either on the rate or the extent of reduction.

We note, however, that even under the optimized preparation conditions, the resulting dispersions of RGO-Ag NP hybrid tended to agglomerate and precipitate in as short a time as one hour. To avoid this, we investigated the addition of appropriate surfactants to the aqueous dispersions. Specifically, several surfactants previously reported to be efficient for the colloidal stabilization of RGO under different physicochemical conditions were tested: ${ }^{53}$ the anionic surfactants poly(sodium 4styrenesulfonate) (PSS), sodium dodecylbenzene sulfonate (SDBS) and sodium taurodeoxycholate hydrate (TDOC), as well as the non-ionic surfactants Pluronic ${ }^{\circledR}$ P123 (P123), polyoxyethylene (100) octadecyl ether (Brij 700), polyoxyethylene sorbitan monooleate (Tween 80), polyoxyethylene sorbitan trioleate (Tween 85), and polyvinylpyrrolidone (PVP). For tests carried out at different surfactant concentrations up to $0.5 \%$ wt./vol., it was determined that only PSS, SDBS and PVP conferred the hybrids with long-term colloidal stability (at least several weeks). SDBS and PVP were then selected and used at the minimum concentration required to stabilize the hybrids for long periods of time, which amounted to 0.075 and $0.010 \%$ wt./vol., respectively. Such surfactant concentrations are much lower than those typically used for the colloidal stabilization of both $\mathrm{RGO}^{53}$ and pristine graphene ${ }^{54}$ in water, which is advantageous from a practical point of view. ICP-MS analysis of surfactant-stabilized samples that were dialyzed to remove unwanted impurities (e.g., unreacted $\mathrm{Ag}(\mathrm{I}), \mathrm{NO}_{3}{ }^{-}$, 
etc) indicated that the amount of metallic silver in the RGO-Ag NP hybrids was 15.2 (SDBS) and $36.4 \mathrm{ppm}$ (PVP), to be compared with a value of $54 \mathrm{ppm}$ for the amount of $\mathrm{Ag}(\mathrm{I})$ originally added as $\mathrm{AgNO}_{3}$ to the $\mathrm{GO}$ suspension. The different values for the two surfactants were a priori unexpected, because the surfactants were added to the dispersion well after ( $\sim 1$ hour) the $\mathrm{GO}, \mathrm{NaBH}_{4}$ and $\mathrm{AgNO}_{3}$ reactants were mixed, but in any case were in agreement with the electrochemical results described further below. Although this question is currently not understood and its elucidation will require further studies, we speculate that the Ag NP growth is not arrested within a few minutes following addition of the reactants, but continues in the presence of the surfactants, which in turn are well known to control the growth of metallic nanostructures in solution. $^{55}$

\subsection{Reduction mechanism of $\mathrm{GO}$ at room temperature in the presence of $\mathrm{NaBH}_{4}$ and $\mathrm{Ag}$} NPS

As mentioned previously, the highly efficient, room-temperature reduction of GO observed here requires the simultaneous presence of $\mathrm{NaBH}_{4}$ and $\mathrm{Ag}$ NPs, whether they be generated in situ from $\mathrm{AgNO}_{3}$ or added as pre-formed objects. Although it is well known that $\mathrm{NaBH}_{4}$ alone is able to reduce colloidal suspensions of $\mathrm{GO}$, the reaction typically requires higher temperatures $\left(\sim 70-95^{\circ} \mathrm{C}\right)$ to be completed in a relatively short time, whereas it proceeds at an exceedingly slow rate at room temperature. ${ }^{48,49}$ Furthermore, the extent of reduction achieved in that case is noticeably lower than the one reported here using $\mathrm{NaBH}_{4}$ and Ag NPs simultaneously. ${ }^{48,49}$ The role of Ag NPs, let alone of $\operatorname{Ag}(\mathrm{I})$, as a reducing agent can be ruled out: contrary to the case of many of their non-noble counterparts, noble metals are not expected to be readily oxidized either by protons or by GO itself. In fact, the standard reduction potential of $\operatorname{Ag}(\mathrm{I}) / \operatorname{Ag}(0)$ is 
$\sim 0.8 \mathrm{~V}$, compared with a value of about $-0.8 \mathrm{~V}$ for $\mathrm{GO}$ at $\mathrm{pH} \sim 4 .{ }^{56,57}$ Consistent with this, we did not observe any sign of reduction in the GO sheets upon addition of preformed $\mathrm{Ag} \mathrm{NPs}$ (or $\mathrm{AgNO}_{3}$ ) to a colloidal suspension of the former, even when the ionic strength of the medium was increased by adding an electrolyte $(\mathrm{NaCl})$ to favor an intimate contact between the sheets and the nanoparticles. ${ }^{58}$ It is therefore reasonable to conclude that reduction of $\mathrm{GO}$ by the $\mathrm{NaBH}_{4}-\mathrm{Ag} \mathrm{NP}$ system is catalytic in nature, with the Ag NPs affording reaction pathways towards deoxygenation of GO that are not accessible to $\mathrm{NaBH}_{4}$ alone at room temperature. To elucidate such reaction pathways, we first note that $\mathrm{Ag}$ has been shown to be catalytically inactive towards the hydrolysis of $\mathrm{NaBH}_{4} \cdot{ }^{36,37}$ By contrast, other metals, such as $\mathrm{Au}, \mathrm{Cu}$ or $\mathrm{Fe}$, are efficient catalysts of this reaction, yielding hydrogen atoms on the metal surface that can eventually reach the GO sheets through spillover and remove their oxygen groups. ${ }^{31,32}$ Such a difference in catalytic activity regarding $\mathrm{NaBH}_{4}$ sets silver apart and should make its promoted reduction of GO fundamentally different from that of other metals.

Albeit $\mathrm{NaBH}_{4}$ is not hydrolyzed on the Ag NP surface, a small but non-negligible extent of hydrolysis does indeed take place spontaneously when $\mathrm{NaBH}_{4}$ is dissolved in water at $\mathrm{pH}$ values below $\sim 12$, with $\mathrm{H}_{2}$ being one of the reaction products. ${ }^{59,60}$ Such an effect is visually apparent due to the gentle but steady evolution of bubbles in freshly prepared $\mathrm{NaBH}_{4}$ solutions. It could be argued that this $\mathrm{H}_{2}$ generated homogeneously in the aqueous medium is dissociated on the Ag NPs to yield atomic hydrogen, but as a general rule $\mathrm{H}_{2}$ dissociation on $\mathrm{Ag}$ surfaces is known to be kinetically impeded by high activation barriers. ${ }^{33-35}$ However, it has also been suggested that under certain circumstances such activation barriers can be significantly lowered. ${ }^{34,35,61}$ Specifically, the presence of an oxide layer has been proposed to favor $\mathrm{H}_{2}$ dissociation on the $\mathrm{Ag}$ surface, ${ }^{34}$ but in our samples we did not find any evidence of oxidized Ag species by 
XPS (only purely metallic Ag was observed; see Fig. 1c), which was also consistent with the observation of a strong SPR band (Fig. 1a, green trace). Furthermore, if an oxide layer was present on the Ag NP surface, it would have been easily removed by the $\mathrm{NaBH}_{4}$ reductant. ${ }^{44}$ For the Ag NPs formed in situ from $\mathrm{AgNO}_{3}$, both the generation of the nanoparticles and the reduction of GO took place under the constant presence of $\mathrm{NaBH}_{4}$, so an oxide layer could have developed on the metal surface neither before nor during the GO reduction process.

Alternatively, extremely small Ag clusters (as opposed to nanometer-sized particles) are thought to facilitate $\mathrm{H}_{2}$ dissociation on account of their very large fraction of undercoordinated surface atoms, especially when supported onto certain systems. ${ }^{35,61}$ In our case, such minute clusters could have been directly generated as an undetected byproduct during the synthesis of the (larger) $\mathrm{Ag}$ NPs from $\mathrm{AgNO}_{3}$, or could have arisen as a result of leaching processes during storage of the Ag NP dispersions (in the case of the pre-formed samples). To test this hypothesis, we centrifuged aqueous dispersions of either the pre-formed Ag NPs or the just-prepared RGO-Ag NP hybrids at the gentlest conditions (typically $10000 \mathrm{~g}$ for $30 \mathrm{~min}$ ) required to sediment them. Were tiny $\mathrm{Ag}$ clusters present in the original dispersion, we would expect them to have remained in the supernatant, and if the clusters were responsible for reduction of the GO sheets, such a fact should become apparent when using the supernatant as reaction medium. Upon addition of $\mathrm{GO}(0.1 \mathrm{mg} \mathrm{mL}-1)$ and $\mathrm{NaBH}_{4}(22.5 \mathrm{mM})$ to the resulting supernatants, we only observed a slight darkening of the suspensions after about 30-40 min. UV-vis spectroscopy revealed that the absorption peak characteristic of GO had red-shifted to positions between 240 and $250 \mathrm{~nm}$, implying that just an exceedingly limited extent of reduction had taken place. ${ }^{48}$ By contrast, as described above, reduction in the presence of Ag NPs occurred in less than 5 min and was much more extensive (red-shift of the 
absorption peak to $268 \mathrm{~nm}$ ). Thus, even though some very minor contribution from minute Ag clusters cannot be completely ruled out, we have to conclude that GO reduction must be essentially driven by the nanometer-sized Ag particles. Consequently, we dismiss dissociation of $\mathrm{H}_{2}$ on potentially active $\mathrm{Ag}$ species (i.e., $\mathrm{Ag}$ in oxidized form or minute Ag clusters) as the main reaction pathway for the observed catalytic reduction of GO.

In addition to $\mathrm{H}_{2}$, the spontaneous hydrolysis of $\mathrm{NaBH}_{4}$ is known to yield the $\mathrm{BH}_{3} \mathrm{OH}^{-}$anion as a rather stable intermediate product, which is further hydrolyzed to give $\mathrm{BO}_{2}^{-}$according to the following equations: $:^{60,62,63}$

$\mathrm{BH}_{4}^{-}+\mathrm{H}_{2} \mathrm{O} \rightarrow \mathrm{BH}_{3} \mathrm{OH}^{-}+\mathrm{H}_{2}$

$\mathrm{BH}_{3} \mathrm{OH}^{-}+\mathrm{H}_{2} \mathrm{O} \rightarrow \mathrm{BO}_{2}^{-}+3 \mathrm{H}_{2}$

Significantly, and contrary to the case of its $\mathrm{BH}_{4}{ }^{-}$counterpart, the $\mathrm{BH}_{3} \mathrm{OH}^{-}$intermediate has been shown to get easily oxidized on Ag surfaces. ${ }^{60}$ Thus, we hypothesize that oxidation of $\mathrm{BH}_{3} \mathrm{OH}^{-}$on the $\mathrm{Ag}$ NPs leads to the charging of the latter with excess electrons, which in turn are transferred to the GO sheets to trigger their reduction. Evidence in support of such hypothesis was obtained by inspecting the characteristics of the SPR band of the Ag NPs. It is well known that the storage of electrons in Au and Ag NPs induces a blue-shift in their SPR band position due to an increased plasmon frequency of the electron gas, the magnitude of the shift being proportional to the amount of excess electrons. ${ }^{64}$ Indeed, when $\mathrm{NaBH}_{4}$ was added to an aqueous dispersion of pre-formed Ag NPs (using the same amounts of both components as those employed for the GO reduction experiments), we observed a blue-shift in their SPR band of about $17 \mathrm{~nm}$, from $\sim 405$ to $388 \mathrm{~nm}$. This result reveals that the Ag NPs become charged in the presence of $\mathrm{NaBH}_{4}$, which would then act as electron reservoirs for the reduction of GO. We stress that this charging is most probably due to oxidation of a product of $\mathrm{BH}_{4}^{-}$ 
hydrolysis (most likely $\mathrm{BH}_{3} \mathrm{OH}^{-}$) rather than to oxidation of $\mathrm{BH}_{4}{ }^{-}$itself: when the hydrolysis reaction was gradually hindered by increasing the $\mathrm{pH}$ of the solution with $\mathrm{NaOH}$, the blue-shift in the position of the SPR band correspondingly diminished (see Fig. 4a, where a linear fit line has been added to assist in the visualization of the trend). When $\mathrm{BH}_{4}{ }^{-}$hydrolysis was almost completely arrested at $\mathrm{pH} \sim 12$, no blue-shift was observed (Fig. 4a), and significantly, no reduction of the GO sheets could be noticed either. This result clearly indicates that the $\mathrm{BH}_{4}{ }^{-}$anion is not directly responsible for the charging of the Ag NPs with excess electrons, which in turn is consistent with the findings by Chatenet et al that the $\mathrm{BH}_{3} \mathrm{OH}^{-}$hydrolysis intermediate is oxidized on $\mathrm{Ag}$ surfaces much more easily than $\mathrm{BH}_{4}{ }^{-}$itself. ${ }^{60}$ For the Ag NPs that were generated in situ from $\mathrm{AgNO}_{3}$ using $\mathrm{NaBH}_{4}$, the presence of the latter should have an effect on the position of their SPR band. In this case, removal of the $\mathrm{NaBH}_{4}$ species through dialysis should induce depletion of the excess electrons from the Ag NPs with a consequent redshift in their SPR band, as was indeed confirmed in our experiments (Fig. 4b). In consequence, based on the previous considerations, we propose a reduction mechanism for the aqueous $\mathrm{GO}$ dispersions with the $\mathrm{NaBH}_{4}-\mathrm{Ag} \mathrm{NP}$ system that involves (i) spontaneous hydrolysis of $\mathrm{BH}_{4}{ }^{-}$in the aqueous medium, (ii) charging of the Ag NPs with excess electrons from the $\mathrm{BH}_{3} \mathrm{OH}^{-}$intermediate and (iii) transfer of these electrons to GO. This mechanism is shown schematically in Fig. 5.

In order to give more insight into the proposed reduction mechanism, EIS studies were carried out as described in the experimental section. Indeed, the relative values of the charge transfer resistance $\left(R_{c t}\right)$ at the electrode solution interface can be an indication of the effective reduction of GO. ${ }^{49}$ Impedance spectra were recorded in a 0.1 $\mathrm{M} \mathrm{KNO}{ }_{3}$ solution at $\mathrm{pH} \sim 7$, containing ferrocyanide and ferrycyanide electroactive species using GC electrodes modified with GO and GO with pre-formed Ag NPs before 
and after incubation in $0.1 \mathrm{M}$ acetate buffer $\mathrm{pH} 5(\mathrm{Ac})$ and $0.5 \mathrm{M} \mathrm{NaOH}$ solutions containing $0.855 \mathrm{mg} \mathrm{mL}^{-1} \mathrm{NaBH}_{4}$ (pH around 8 and 14, respectively). Figure 6 shows the Nyquist impedance plots of a GO and Ag NPs on GC electrode before (red trace) and after incubation in the above mentioned solutions (blue and green traces, respectively). It also shows the impedance spectrum of the bare GC electrode (black trace) for comparison. Upon modification of the electrode surface with GO and Ag NPs, the $\mathrm{R}_{\mathrm{ct}}$ increases significantly from $0.80 \mathrm{k} \Omega$ to $2.79 \mathrm{k} \Omega$. This difference stems from (1) the non-conductive nature of the deposited GO layer modified with the Ag NPs, considering that the latter must be intercalated between the GO sheets but physically isolated from each other, and (2) the electrostatic repulsion that should take place between oxygen-containing groups of the $\mathrm{GO}$, which are partly deprotonated at the $\mathrm{pH}$ of the $\mathrm{KNO}_{3}$ solution $(\sim 7) ;{ }^{65}$ and the negatively charged electroactive species present in solution. Upon incubation of the modified electrode in the $\mathrm{NaOH}$ and Ac solutions containing $\mathrm{NaBH}_{4}$, the values of the $\mathrm{R}_{\mathrm{ct}}$ oppositely changed. The former increased significantly, from $2.79 \mathrm{k} \Omega$ to $3.79 \mathrm{k} \Omega$, which must be related to further deprotonation of oxygen-containing groups of the $\mathrm{GO}$ in the $\mathrm{NaOH}$ solution ${ }^{65}$ and thus to a higher density of negative charges on the surface of the modified electrode. However, the modified electrode incubated in the Ac solution gave rise to a clear decrease of the $R_{c t}$, from $2.79 \mathrm{k} \Omega$ to $1.93 \mathrm{k} \Omega$. Here, some deprotonation of the oxygen-containing groups may also occur considering the difference in $\mathrm{pH}$ between the measurement and the incubation solutions (i. e., 8 vs. 7 ), so the decrease in the $\mathrm{R}_{\mathrm{ct}}$ values must result from a lower density of negative charges on the surface of the modified GC electrode and thus a lower density of oxygen-containing groups as well as a more conductive surface, which is consistent with reduction of GO taking place under these experimental conditions. This study was repeated with a GC electrode just modified with GO, i. e., in 
the absence of $\mathrm{Ag}$ NPs (Nyquist plots not shown). The value of $\mathrm{R}_{\mathrm{ct}}$ increased from 2.83 $\mathrm{k} \Omega$ to $6.80 \mathrm{k} \Omega$ upon incubation in the Ac buffer solution containing $\mathrm{NaBH}_{4}$, which indicates that a deprotonation of the oxygen-containing groups of the GO may have just taken place in this case, but not reduction of the GO sheets has occurred, as expected.

\subsection{Catalytic and electrochemical performance of the RGO-Ag NP hybrids}

The reduction of 4-NP to 4-AP with $\mathrm{NaBH}_{4}$ in aqueous medium at room temperature is often used as a model reaction to probe the catalytic performance of metal nanoparticles. Such a reaction is also of practical importance as one of the main steps in the synthesis of widely employed pharmaceutical compounds (e.g., paracetamol). ${ }^{66}$ We tested the performance of the RGO-Ag NP hybrids prepared here towards this reaction. Fig. 7a shows typical UV-vis absorption spectra of aqueous solutions of (i) 4-NP at the slightly acidic $\mathrm{pH}$ of deionized water (black plot), (ii) deprotonated 4-NP (i.e., 4-nitrophenoxide ion), formed in the basic medium generated by the presence of $\mathrm{NaBH}_{4}$ (green plot), and (iii) the product of 4-NP reduction, 4-AP (more specifically, its aminophenoxide anion; violet plot). The reaction progress can be followed by monitoring the decay of the characteristic absorption peak of 4-nitrophenoxide at $400 \mathrm{~nm}$. No conversion of 4-NP to 4-AP (i.e., no decay of the $400 \mathrm{~nm}$ peak) was observed to occur in the absence of RGOAg NP hybrids, confirming their catalytic role. Fig. 7b shows experimental kinetic profiles obtained for the reaction in the presence of SDBS-stabilized (black squares) and PVP-stabilized (grey squares) RGO-Ag NP hybrids. The residual absorbance observed in both cases after completion of the reaction is due to the catalyst itself, which also absorbs at $400 \mathrm{~nm}$ (see Fig. 1a, green plot). Because $\mathrm{NaBH}_{4}$ was added in large excess compared to 4-NP (600:1 molar ratio, see Experimental section), it is safe to assume that its concentration remains essentially constant throughout the reduction reaction, so 
the reaction rate can be considered not to depend on it. Also, considering that the time evolution of the absorption peak at $400 \mathrm{~nm}$ could be well fitted to an exponential decay (Fig. 7b, solid lines), the reduction reaction can be regarded to obey a pseudo-first-order kinetic behavior with respect to 4-NP, so that:

$$
\frac{d[4-\mathrm{NP}]}{d \mathrm{t}}=-k_{a p p}[4-\mathrm{NP}]
$$

, where [4-NP] is the concentration of 4-NP and $k_{a p p}$ is the apparent rate constant. Using the SDBS- and PVP-stabilized dispersions of RGO-Ag NPs hybrid as catalysts, the rate constants were calculated to be $k_{a p p}=(1.7 \pm 0.1) \times 10^{-1} \mathrm{~s}^{-1}$ and $(1.2 \pm 0.1) \times 10^{-2} \mathrm{~s}^{-1}$, respectively.

To compare the catalytic performance of these hybrids with that of other $\mathrm{Ag}$ catalysts reported in the literature, the observed rate constant was normalized to the mass of Ag employed per unit volume, as determined by ICP-MS, yielding estimated values of 11 and $0.33 \mathrm{~L} \mathrm{~g}^{-1} \mathrm{~s}^{-1}$ for the SDBS- and PVP-stabilized dispersions, respectively. The SDBS-stabilized hybrid is seen to exhibit a remarkable activity, indeed among the highest reported to date for this reaction using Ag as a catalyst (see Table 1). ${ }^{67-72}$

Next, the electrochemical behavior of the RGO-Ag NP hybrids was tested towards the catalytic reduction of $\mathrm{H}_{2} \mathrm{O}_{2}$, which is an environmentally friendly but strong oxidant agent increasingly demanded in industrial oxidation processes. ${ }^{73}$ Direct oxidation of organic molecules by $\mathrm{H}_{2} \mathrm{O}_{2}$ requires the use of a catalyst, such as transition metals and enzyme biomolecules. ${ }^{74-77}$ The performance of the RGO-Ag NP hybrids synthesized in this work was assessed by mimicking the catalytic reaction using electrochemical processes, where the organic species are substituted by a SPCE. Fig. 8a depicts cyclic voltammetric signals recorded with SPCEs modified with SDBS-stabilized and PVPstabilized hybrids in a PBS solution containing $0 \mathrm{mM}$ and $3 \mathrm{mM} \mathrm{H}_{2} \mathrm{O}_{2}$. It also includes 
those signals recorded with a SPCE modified with the PVP-stabilized hybrid, which was treated with $\mathrm{HNO}_{3}$ and then dialyzed in order to strip the Ag NPs off the RGO surface. Both PVP-stabilized and SBDS-stabilized hybrids show electrocatatytic activity towards the reduction of $\mathrm{H}_{2} \mathrm{O}_{2}$, with voltammetric signals peaking at $-0.6 \mathrm{~V}$ and $-0.7 \mathrm{~V}$, respectively. These signals can be ascribed to a two-step two-electron electrochemical process that takes place in either acidic or alkaline media ${ }^{78,79}$ The response of the hybrid containing no Ag NPs shows a peak at around $-0.5 \mathrm{~V}$ in PBS that increased upon the addition of $\mathrm{H}_{2} \mathrm{O}_{2}$ but whose peak current is at least six-fold smaller than that recorded with hybrids containing Ag NPs. This peak could be ascribed to the reduction of $\mathrm{O}_{2}$ at the RGO surface. ${ }^{80}$ The presence of $\mathrm{O}_{2}$ in solution could be due to its non-complete removal during deareation with $\mathrm{N}_{2}$, but could also appear in solution due to the decomposition of $\mathrm{H}_{2} \mathrm{O}_{2}$ to $\mathrm{O}_{2}$ and $\mathrm{H}_{2} \mathrm{O}$ catalyzed by $\mathrm{Ag}$ impurities that may still be present in the samples. ${ }^{76}$

From the observed peak potential values, it appears that catalytic reduction of $\mathrm{H}_{2} \mathrm{O}_{2}$ is kinetically somewhat easier with the PVP-stabilized hybrid. Also, the peak current measured with this material was higher. The difference in the amount of metallic Ag (higher amount in the PVP-stabilized material than in the SBDS-stabilized one) shown above is very likely to be responsible for the higher peak current measured with the former material, but could also have an effect on the observed peak potential difference. In order to provide more insight into the different content in metallic Ag in the samples, a cyclic potential scan was carried out in PBS from $-0.2 \mathrm{~V}$ to $+0.5 \mathrm{~V}$ to strip off the $\mathrm{Ag}$ from the hybrid material. An anodic peak at around $+0.1 \mathrm{~V}$ was observed due to oxidation of $\operatorname{Ag}(0)$ to $\operatorname{Ag}(\mathrm{I})$ (data not shown). By measuring the area under the recorded peak, we could estimate that the PVP-stabilized material contained about 2.7 times more Ag than its SBDS-stabilized counterpart. This result is consistent with the data 
obtained from the ICP-MS measurements given above. It was also mentioned above that the higher amount of metallic Ag in the PVP-stabilized material could be due to further growth processes controlled by the surfactant. It has been reported that an increase in Ag NP size induces a shift in the potential of the catalytic cathodic signal towards more positive values. ${ }^{76}$ Therefore, small differences in the size of the Ag NPs generated in the presence of PVP and SDBS (larger size in the case of PVP) could be responsible for the differences observed in voltammetric behavior of the two materials.

Fig. $8 \mathrm{~b}$ depicts the chronoamperometric response profiles of both hybrids measured at a set overpotential of $-0.75 \mathrm{~V}$, at which the cathodic current generated by the reduction of $\mathrm{H}_{2} \mathrm{O}_{2}$ catalyzed by the Ag NPs of either hybrid material could be recorded. Steady-state current responses were recorded for each analyte concentration measured, the response time being of $3 \mathrm{~s}$ in both cases. From these results, the corresponding calibration curves were plotted. Both PVP- and SBDS-stabilized materials showed a linear behavior in a wide $\mathrm{H}_{2} \mathrm{O}_{2}$ concentration range from $10 \mu \mathrm{M}$ to $10 \mathrm{mM}$ (sensitivity = $-0.034 \mu \mathrm{A} \mu \mathrm{M}^{-1} ; \mathrm{n}=12 ; \mathrm{r}=0.997$ ) and from $20 \mu \mathrm{M}$ to $10 \mathrm{mM}$ (sensitivity $=-0.016 \mu \mathrm{A}$ $\mu \mathrm{M}^{-1} ; \mathrm{n}=12 ; \mathrm{r}=0.998$ ), respectively. A limit of detection (LOD) of $80 \mu \mathrm{M}$ was estimated for both hybrids, this being the lowest concentration measured whose signal was equal or higher than three times the noise of the chronoamperometric measurements. Even though the PVP-stabilized hybrid appeared to be more sensitive towards the reduction of $\mathrm{H}_{2} \mathrm{O}_{2}$, the higher response noise recorded gave rise to the same estimated LOD. These analytical values compare well with those previously reported for RGO-Ag NP hybrids prepared using other synthetic approaches. ${ }^{81-83}$

The experimental fact that SDBS-stabilized Ag NP-RGO hybrid is a better catalyst than the PVP-stabilized one for the reduction of 4-NP to 4-AP with $\mathrm{NaBH}_{4}$ is not in contradiction with the fact that the PVP-stabilized one performs better as a 
catalyst for the electrochemical reduction of $\mathrm{H}_{2} \mathrm{O}_{2}$. As mentioned above, the hybrids differ from one another in some extent (one is partially covered with the ionic surfactant SDBS while the other is covered by the non-ionic surfactant PVP) and thus can be considered to be different catalysts. It is not uncommon that a catalyst $\mathrm{A}$ is better than another one B for a given process but the former performs worse than the latter in another reaction. The two processes researched here are very different and thus it is possible that two dissimilar catalysts perform differently for them.

\section{Conclusions}

We have shown that Ag nanoparticles (Ag NPs), either pre-formed or generated in situ, can efficiently catalyze the reduction of aqueous graphene oxide (GO) dispersions with $\mathrm{NaBH}_{4}$ at room temperature. Different to the case of other metals that are known to act as catalysts for this reaction, we have proposed that Ag-catalyzed reduction of GO is triggered by the spontaneous hydrolysis of $\mathrm{NaBH}_{4}$ in the aqueous medium, which generates an intermediate product $\left(\mathrm{BH}_{3} \mathrm{OH}^{-}\right)$that is readily oxidized on the $\mathrm{Ag} \mathrm{NP}$ surface. This leads to charging of the Ag NPs with excess electrons, which are then transferred to the GO sheets to induce their reduction. We have also demonstrated that the reduced GO-Ag NP hybrids generated by this extremely simple, room-temperature process are potentially useful in catalysis and electrochemistry, as exemplified by their high catalytic activity in the reduction of 4-nitrophenol to 4-aminophenol and the electrochemical reduction of $\mathrm{H}_{2} \mathrm{O}_{2}$.

\section{Acknowledgements}


Financial support from the Spanish MINECO and the European Regional Development Fund through project MAT2011-26399 is gratefully acknowledged. M.A.V. and M.J.F.-M. are indebted to MINECO for their pre-doctoral (FPI) contracts.

\section{References}

1 A.K. Geim and K.S. Novoselov, Nature Mater., 2007, 6, 183-191.

2 A.K. Geim, Science, 2009, 324, 1530-1534.

3 K.S. Novoselov, V.I. Fal'ko, L. Colombo, P.R. Gellert, M.G. Schwab and K. Kim, Nature, 2012, 490, 192-200.

4 F. Schwierz, Nature Nanotech., 2010, 5 , 487-496.

5 F. Bonaccorso, Z. Sun, T. Hasan and A.C. Ferrari, Nature Photon., 2010, 4, 611-622.

6 Y.X. Liu, X.C. Dong and P. Chen, Chem. Soc. Rev., 2012, 41, 2283-2307.

7 B. Luo, S.M. Liu and L.J. Zhi, Small, 2012, 8, 630-646.

8 J.R. Potts, D.R. Dreyer C.W. Bielawski and R.S. Ruoff, Polymer, 2011, 52, 5-25.

9 B.F. Machado and P. Serp, Catal. Sci. Technol., 2012, 212, 54-75.

10 H.Y. Mao, S. Laurent, W. Chen, O. Akhavan, M. Imani, A.A. Ashkarran and M. Mahmoudi, Chem. Rev., 2013, 113, 3407-3424.

11 F. Bonaccorso, A. Lombardo, T. Hasan, Z. Sun, L. Colombo and A.C. Ferrari, Mater. Today, 2012, 15, 564-589.

12 S. Park and R.S. Ruoff, Nature Nanotech., 2009, 4, 217-224.

13 D.R. Dreyer, S. Park, C.W. Bielawski and R.S. Ruoff, Chem. Soc. Rev., 2010, 39, 228-240.

14 O.C. Compton and S.T. Nguyen, Small, 2010, 6, 711-723.

15 S. Pei and H.-M. Cheng, Carbon, 2012, 50, 3210-3228.

16 S. Mao, H. Pu and J. Chen, RSC Adv., 2012, 2, 2643-2662. 
17 Z. Fan, K. Wang, T. Wei, J. Yan, L. Song and B. Shao, Carbon, 2010, 48, 16861689.

18 V.H. Pham, H.D. Pham, T.T. Dang, S.H. Hur, E.J. Kim, B.S. Kong, S. Kim and J.S. Chung, J. Mater. Chem., 2012, 22, 10530-10536.

19 Z.-J. Fan, W. Kai, J. Yan, T. Wei, L.-J. Zhi, J. Feng, Y. Ren, L.-P. Song and F. Wei, ACS Nano, 2011, 5, 191-198.

20 X. Mei and J. Ouyang, Carbon, 2011, 49, 5389-5397.

21 Y. Liu, Y. Li, M. Zhong, Y. Yang, Y. Wen and M. Wang, J. Mater. Chem., 2011, 21, 15449-15455.

22 R.S. Dey, S. Hajra, R.K. Sahu, C.R. Raj and M.K. Panigrahi, Chem. Commun., 2012, 48, 1787-1789.

23 S. Yang, W. Yue, D. Huang, C. Chen, H. Lin and X. Yang, RSC Adv., 2012, 2, 88278832.

24 P. Liu, Y. Huang and L. Wang, Mater. Lett., 2013, 91, 125-128.

25 R. Krishna, E. Titus, L.C. Costa, J.C.J.M.D.S. Menezes, M.R.P. Correia, S. Pinto, J. Ventura, J.P. Araújo, J.A.S. Cavaleiro and J.J.A. Gracio, J. Mater. Chem., 2012, 22, 10457-10459.

26 B.K. Barman, P. Mahanandia and K.K. Nanda, RSC Adv., 2013, 3, 12621-12624.

27 C. K. Chua and M. Pumera, Chem. Soc. Rev., 2014, 43, 291-312.

28 M. Liang, J. Wang, B. Luo, T. Qiu and L. Zhi, Small, 2012, 8, 1180-1184.

29 T.T. Dang, V.H. Pham, B.K. Vu, S.H. Hur, E.W. Shin, E.J. Kim and J.S. Chung, Mater. Lett., 2012, 86, 161-164.

30 V.H. Pham, T.T. Dang, K. Singh, S.H. Hur, E.W. Shin, J.S. Kim, M.A. Lee, S.H. Baeck and J.S. Chung, J. Mater. Chem. A, 2013, 1, 1070-1077. 
31 Q. Zhuo, Y. Ma, J. Gao, P. Zhang, Y. Xia, Y. Tian, X. Sun, J. Zhong and X. Sun, Inorg. Chem., 2013, 52, 3141-3147.

32 Q. Zhuo, J. Gao, M. Peng, L. Bai, J. Deng, Y. Xia, Y. Ma, J. Zhong and X. Sun, Carbon, 2013, 52, 559-564.

33 K. Christmann, Surf. Sci. Rep., 1988, 9, 1-163.

34 A.B. Mohammad, K.H. Lim, I.V. Yudanov, K.M. Neyman and N. Rösch, Phys. Chem. Chem. Phys., 2007, 9, 1247-1254.

35 T. Gomez, E. Florez, J.A. Rodriguez and F. Illas, J. Phys. Chem. C, 2011, 115, 11666-11672.

36 R.X. Feng, H. Dong, Y.L. Cao, X.P. Ai and H.X. Yang, Int. J. Hydrogen Energy, 2007, 32, 4544-4549.

37 A.E. Sanli, A. Aytaç, B.Z. Uysal and M.L. Aksu, Catal. Today, 2011, 170, 120-125.

38 T. Wu, S. Liu, Y Luo, W. Lu, L. Wang and X. Sun, Nanoscale, 2011, 3, 2142-2144.

39 S. Dutta, C. Ray, S. Sarkar, M. Pradhan, Y. Negishi and T. Pal, ACS Appl. Mater. Interfaces, 2013, 5, 8724-8732.

40 J. Liu, S. Fu, B. Yuan, Y. Li and Z. Deng, J. Am. Chem. Soc., 2010, 132, 7279-7281.

41 W.S. Hummers Jr. and R.E. Offeman, J. Am. Chem. Soc., 1958, 80, 1339.

42 J. I. Paredes, S. Villar-Rodil, P. Solís-Fernández, A. Martínez-Alonso and J. M. D. Tascón, Langmuir, 2009, 25, 5957-5968.

43 C. Fernández-Sánchez, C. J. McNeil and K. Rawson, Trends Anal. Chem., 2005, 24, $37-48$.

44 N N. Pradhan, A. Pal and T. Pal, Colloids Surf. A, 2002, 196, 247-257.

45 M. J. Fernández-Merino, L. Guardia, J. I. Paredes, S. Villar-Rodil, A. MartínezAlonso and J. M. D. Tascón, RSC Adv., 2013, 3, 18623-18331. 
46 D. Li, M.B. Müller, S. Gilje, R.B. Kaner and G.G. Wallace, Nature Nanotech., 2008, 3, 101-105.

47 J.I. Paredes, S. Villar-Rodil, A. Martínez-Alonso and J.M.D. Tascón, Langmuir, 2008, 24, 10560-10564.

48 M.J. Fernández-Merino, L. Guardia, J.I. Paredes, S. Villar-Rodil, P. Solís-Fernández, A. Martínez-Alonso and J.M.D. Tascón, J. Phys. Chem. C, 2010, 114, 6426-6432.

49 C. K. Chua, M. Pumera, J. Mater. Chem. A, 2013, 1, 1892-1898.

50 D. D. Evanoff Jr. and G. Chumanov, ChemPhysChem, 2005, 6, 1221-1231.

51 G. Zhang, S. Sub, D. Yang, J.-P. Dodelet and E. Sacher, Carbon, 2008, 46, 196-205. 52 B. V. Crist, in Handbook of Monochromatic XPS Spectra. The Elements \& Native Oxides. XPS International LLC. California, USA, 2004, vol. 1, pp.1-4.

53 M.J. Fernández-Merino, J.I. Paredes, S. Villar-Rodil, L. Guardia, P. Solís-Fernández, D. Salinas-Torres, D. Cazorla-Amorós, E. Morallón, A. Martínez-Alonso and J.M.D. Tascón, Carbon, 2012, 50, 3184-3194.

54 L. Guardia, M.J. Fernández-Merino, J.I. Paredes, P. Solís-Fernández, S. Villar-Rodil, A. Martínez-Alonso and J.M.D. Tascón, Carbon, 2011, 49, 1653-1662.

55 W. Zhang, X. Qiao and J. Chen, Mater. Sci. Eng. B, 2007, 142, 1-15.

56 M. Zhou, Y. Wang, Y. Zhai, J. Zhai, W. Ren, F. Wang and S. Dong, Chem. Eur. J. , 2009, 15, 6116-6120.

57 Y. Shao, J. Wang, M. Engelhard, C. Wang and Y. Lin, J. Mater. Chem., 2010, 20, 743-748.

58 F. Bei, X. Hou, S.L.Y. Chang, G.P. Simon and D. Li, Chem. Eur. J., 2011, 17, 59585964.

59 E.Y. Marrero-Alfonso, A.M. Beaird, T.A. Davis and M.A. Mathews, Ind. Eng. Chem. Res., 2009, 48, 3703-3712. 
60 M. Chatenet, F. Micoud, I. Roche and E. Chainet, Electrochim. Acta, 2006, 51, $5459-5467$.

61 S. Moncho, E.N. Brothers and B.G. Janesko, J. Phys. Chem. C, 2013, 117, 74877496.

62 J.A. Gardiner and J.W. Collat, J. Am. Chem. Soc., 1964, 86, 3165-3166.

63 J. Andrieux, U.B. Demirci, J. Hannauer, C. Gervais, C. Goutaudier and P. Miele, Int. J. Hydrogen Energy, 2011, 36, 224-233.

64 A. Takai and P.V. Kamat, ACS Nano, 2011, 5, 7369-7376.

65 B. Konkena and S. Vasudevan, J. Phys. Chem. Lett., 2012, 3, 867-872.

66 P. Hervés, M. Pérez-Lorenzo, L.M. Liz-Marzán, J. Dzubiella, Y Lu and M. Ballauff, Chem. Soc. Rev. , 2012, 41, 5577-87.

67 E. K. Jeon, E. Seo, E. Lee, W. Lee, M.-K. Um and B.-S. Kim. Chem. Comm., 2013, 49, 3392-3394.

68 P. Zhang, C. Shao, Z. Zhang, M. Zhang, J. Mu, Z. Guo and Y. Liu, Nanoscale, 2011, 3, 3357-3363.

69 B. Baruah, G. J. Gabriel, M. J. Akbashev and M. E. Booher, Langmuir, 2013, 29, 4225-4234.

70 Md. H. Rashid and T. K. Mandal, J. Phys. Chem. C, 2007, 111, 16750-16760.

71 W. Zhang, F. Tan, W. Wang, X. Qiu, X. Qiao and J. Chen, J. Hazard. Mater., 2012, 217-218, 36-42.

72 S. Tang, S. Vongehr and X. Meng, J. Mater. Chem., 2010, 20, 5436.

73 J. Piera and J-E. Bäckvall, Angew. Chem. Int. Ed., 2008, 47, 3506 - 3523.

74 Y. Chen, H. Cao, W. Shi, H. Liu and Y. Huang, Chem. Comm., 2013, 44, 5013-5015.

75 H. Wei and E. Wang, Anal. Chem., 2008, 80, 2250-2254. 
76 C. M. Welch, C. E. Banks, A. O. Simm and R. G. Compton, Anal. Bioanal. Chem., 2005, 382, 12-21.

77 B. Ibarlucea, C. Fernández-Sánchez, S. Demming, S. Büttgenbach and A. Llobera, Analyst, 2011, 136, 3496-3502.

78 M. Honda, T. Kodera and H. Kita, Electrochim. Acta, 1983, 28, 727-733.

79 M. Honda, T. Kodera and H. Kita, Electrochim. Acta, 1986, 31, 377-383.

80 E. P. Randviir, C. E. Banks, Electroanal., 2014, 26, 76-83.

81 S. Liu, L. Wang, J. Tian, Y. Luo, X. Zhang, X. Sun, J. Coll. Interf. Sci., 2011, 363, $615-619$.

82 X. Liu, X. Xu, H. Zhu, X. Yang, Anal. Methods, 2013, 5, 2298-2304.

83 M. Y. Wang, T. Shen, M. Wang, D. Zhang, J. Chen, Mat. Lett., 2013, 107, 311-314. 
Table 1. Comparison of rate constants normalized to Ag NP concentration obtained for the reduction of 4-NP with $\mathrm{NaBH}_{4}$ using a number of Ag NP-based catalysts.

Catalytic system Rate constant

Reference

$$
\left(\mathrm{L} \mathrm{g}^{-1} \mathrm{~s}^{-1}\right)
$$

SDBS-stabilized Ag NP-RGO hybrids

0.33

This work

PVP-stabilized Ag NP-RGO hybrids

This work

Ag NP-GO-dopamine hybrids

3.8

67

Ag NPs on polymer-derived carbon 3.3

nanofibers

Ag NPs stabilized by cationic 1.4

polynorbornenes

Spherical (and dendritic) Ag NPs

$1.4-4.0$

70

Ag nanodendrites

0.01

71

Ag NPs embedded in porous carbon spheres $\quad 0.01$

72 
Figure 1.
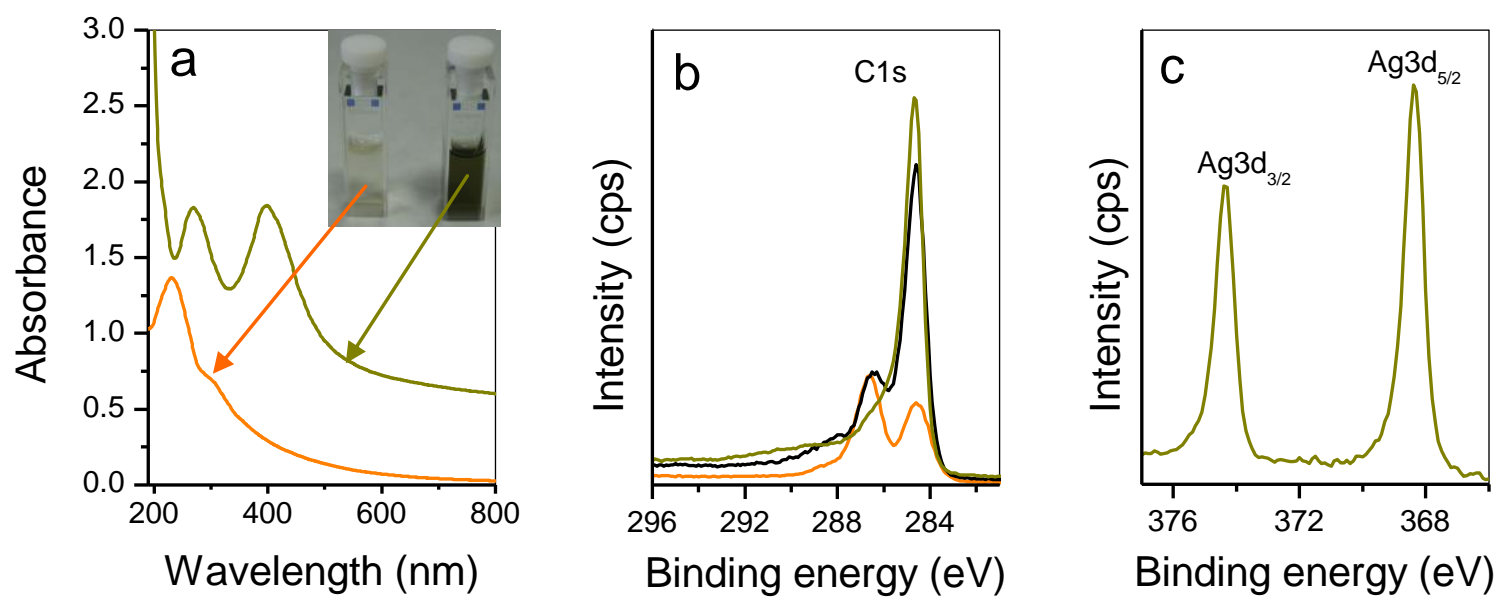
Figure 2

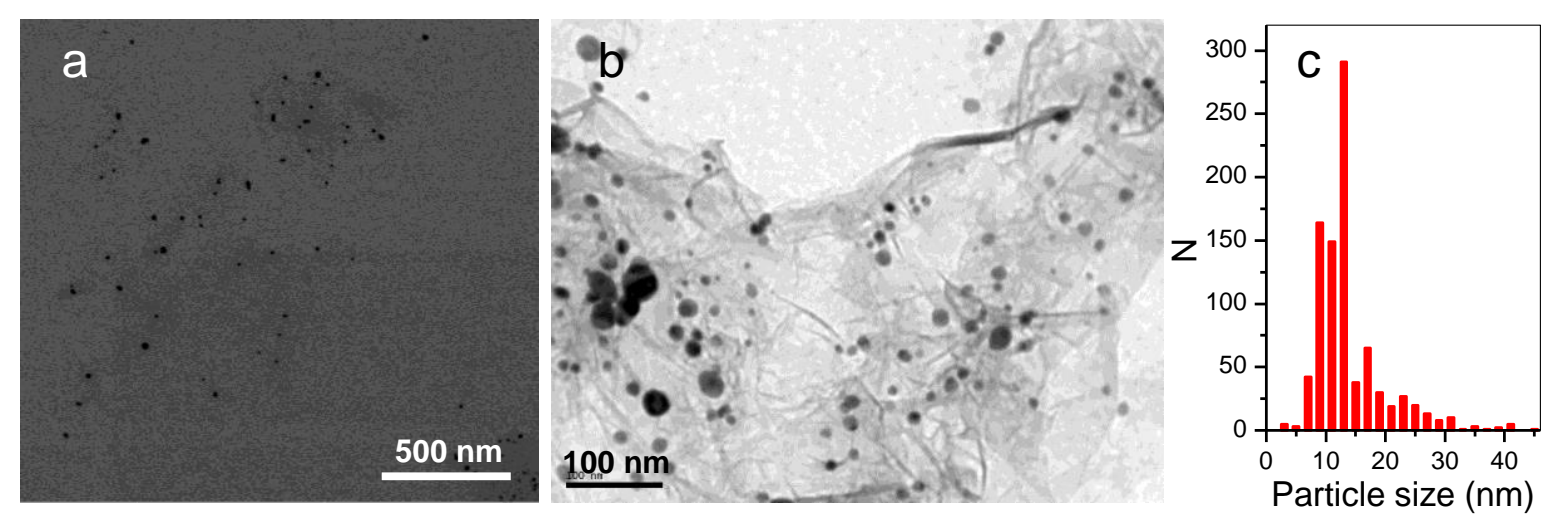


Figure 3.

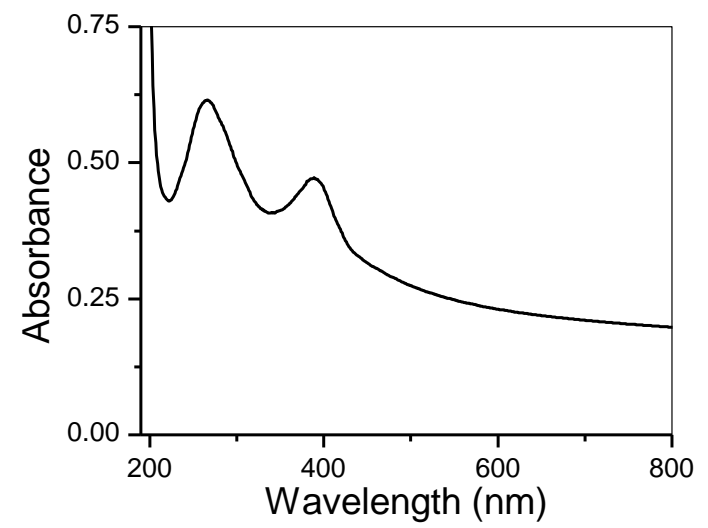


Figure 4.
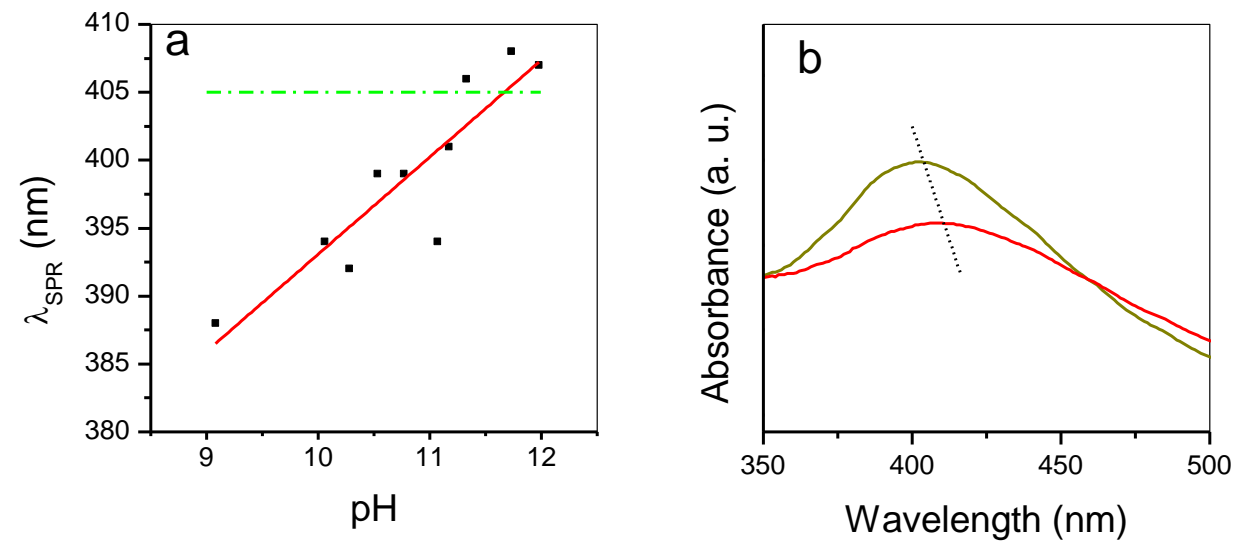
Figure 5.

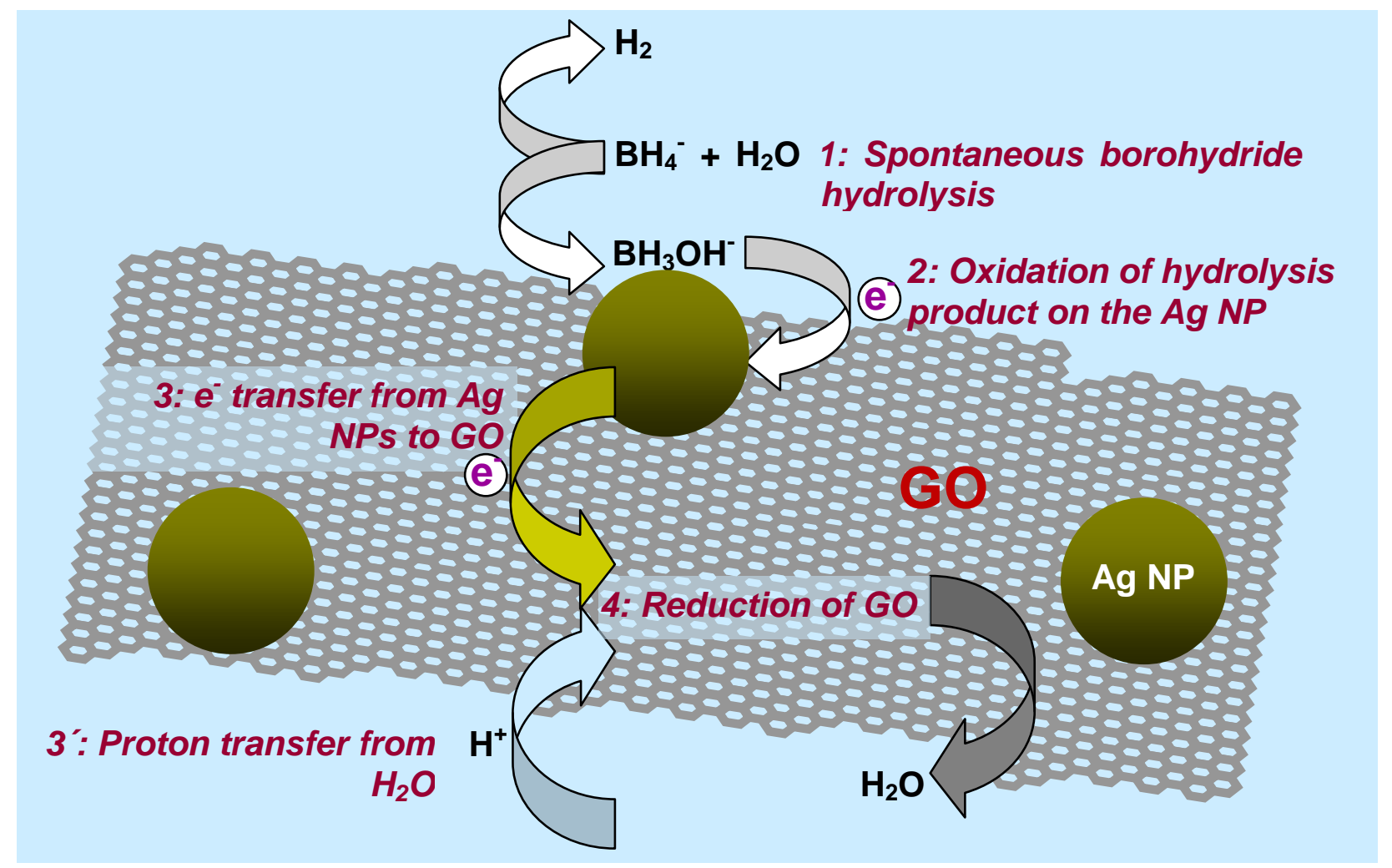


Figure 6.

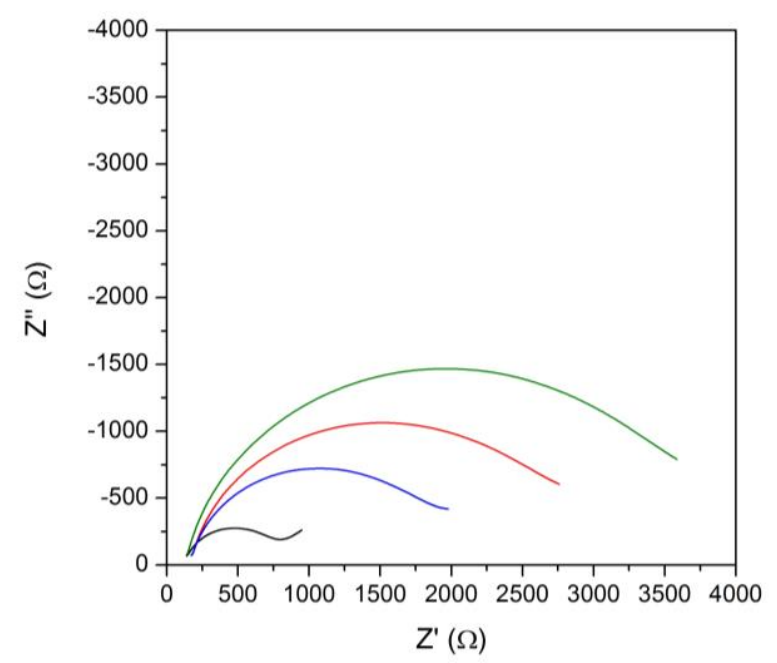


Figure 7.
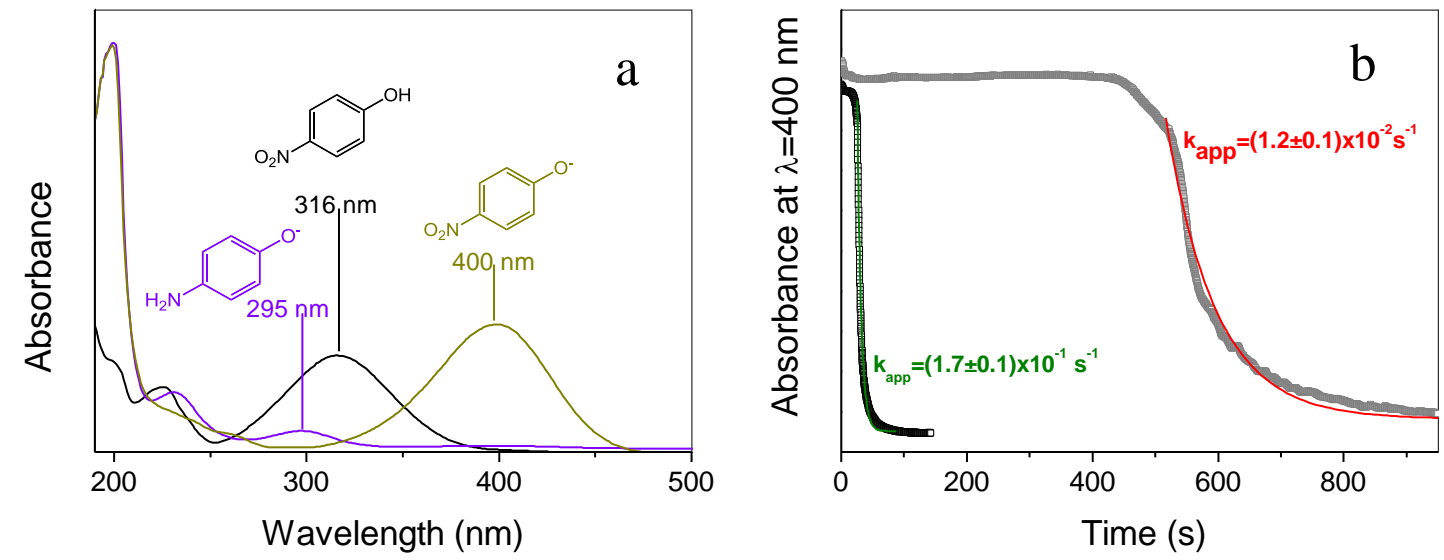
Figure 8.
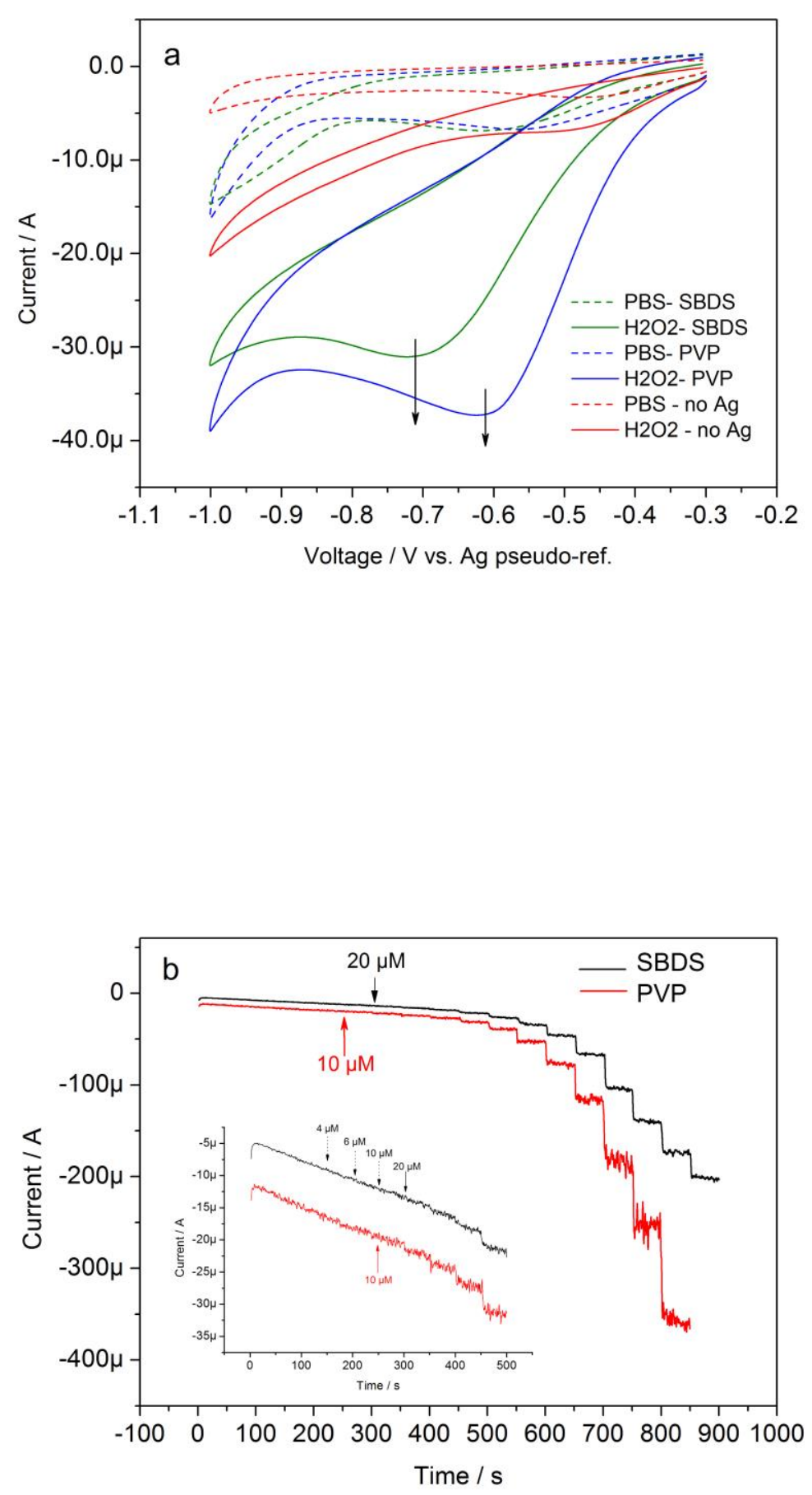


\section{Captions to Figures}

Figure 1. Spectroscopic evidence for reduction of GO and $\mathrm{Ag}(\mathrm{I})$ : (a) UV-vis absorption spectra of the starting, unreduced GO dispersion (orange trace) and the same dispersion after treatment with $\mathrm{NaBH}_{4}$ in the presence of $\mathrm{AgNO}_{3}$ (green trace). Inset: digital pictures of the corresponding dispersions. (b) High resolution XPS C 1s core level spectra of unreduced GO (orange trace), GO after treatment with $\mathrm{NaBH}_{4}$ at $95{ }^{\circ} \mathrm{C}$ (black trace), and $\mathrm{GO}$ after treatment with $\mathrm{NaBH}_{4}$ in the presence of $\mathrm{AgNO}_{3}$ at room temperature (green trace). The spectra have been normalized to their area and re-scaled by multiplying by the $\mathrm{C}$ at. $\%$ of each sample calculated from the corresponding survey spectra. (c) High resolution XPS Ag 3d core level spectrum of GO treated with $\mathrm{NaBH}_{4}$ in the presence of $\mathrm{AgNO}_{3}$ at room temperature.

Figure 2. Microscopic characterization of GO treated with $\mathrm{NaBH}_{4}$ in the presence of $\mathrm{AgNO}_{3}$ : (a) Representative STEM and (b) TEM images. (c) Histogram of nanoparticle size distribution derived from a pool of 900 nanoparticles measured in the TEM images.

Figure 3. UV-vis absorption spectrum of a GO dispersion treated with $\mathrm{NaBH}_{4}$ in the presence of pre-formed Ag NPs.

Figure 4. (a) Position of the SPR band ( $\left.\lambda_{\mathrm{SPR}}\right)$ for aqueous dispersions of pre-formed Ag NPs $(\sim 20 \mathrm{~nm}$ in diameter $)$ in the presence of $\mathrm{NaBH}_{4}(22.5 \mathrm{mM})$ as a function of $\mathrm{pH}$ of the medium. A linear fit of the data (red line) has been added to highlight the observed trend. The green line indicates the value of $\lambda_{\mathrm{SPR}}(\sim 405 \mathrm{~nm})$ for the Ag NPs in the absence of $\mathrm{NaBH}_{4}$. (b) UV-vis absorption spectra for PVP-stabilized (0.01 \%wt./vol.) 
RGO-Ag NP hybrid before (green trace) and after (red) dialysis. A dotted line has been added to highlight the red-shift in the position of the SPR band of the Ag NPs induced by the dialysis treatment.

Figure 5. Schematic illustrating the proposed mechanism for the reduction of aqueous GO dispersions with $\mathrm{NaBH}_{4}$ catalyzed by Ag NPs, involving (1) the spontaneous hydrolysis of $\mathrm{BH}_{4}{ }^{-}$in the aqueous medium, (2) charging of the Ag NPs with excess electrons from the oxidation of the $\mathrm{BH}_{3} \mathrm{OH}^{-}$hydrolysis intermediate and (3) transfer of these excess electrons to GO.

Figure 6. Nyquist impedance plots recorded with a GC electrode, bare (black trace) and modified with GO and AgNPs (red trace), and after incubation in Ac (blue trace) and $\mathrm{NaOH}$ solutions containing $\mathrm{NaBH}_{4}$ (green trace). Experimental conditions: $0.1 \mathrm{M} \mathrm{KNO}_{3}$ containing $1 \mathrm{mM}$ ferrocyanide and $1 \mathrm{mM}$ ferricyanide electroactive species; $10 \mathrm{kHz}-10$ $\mathrm{Hz}$ frequency range, $10 \mathrm{mV}$ amplitude, $+0.134 \mathrm{~V} \mathrm{DC}$ potential.

Figure 7. (a) UV-vis absorption spectra of 4-nitrophenol (black curve), 4nitrophenoxide ion (green), and 4-aminophenoxide ion (violet). The characteristic absorption peak of 4-nitrophenoxide at $400 \mathrm{~nm}$ can be used to monitor its conversion to 4-aminophenoxide by reduction with $\mathrm{NaBH}_{4}$. (b) Plot of absorbance at $400 \mathrm{~nm}$ for the reduction 4-nitrophenoxide with $\mathrm{NaBH}_{4}$ as catalyzed by RGO-Ag NP hybrids stabilized in aqueous dispersion by SDBS (black squares) and PVP (gray squares). The experimental kinetic profiles could be fitted to exponential decay functions, which are shown as overlaid green and red lines, respectively. The corresponding apparent rate 
constants $\left(\mathrm{k}_{\mathrm{app}}\right)$ are also shown. Experimental conditions: [4-nitrophenol] $=0.06 \mathrm{mM}$; $\left[\mathrm{NaBH}_{4}\right]=36 \mathrm{mM} ;[\mathrm{Ag} \mathrm{NP}] \sim 0.3-0.7 \mu \mathrm{g} \mathrm{mL}-1$.

Figure 8. (a) Cyclic voltammograms recorded with SPCEs modified with SBDSstabilized and PVP-stabilized hybrids. SPCEs modified with PVP-stabilized hybrid treated with $\mathrm{HNO}_{3}$ to strip off the Ag NPs were also tested for comparison purposes. Scan rate: $50 \mathrm{mV} / \mathrm{s}$. Black arrows indicate the peak voltages of the recorded cathodic catalytic signals. (b) Chronoamperometric responses of SPCEs modified with PVP and SDBS-stabilized hybrids to increasing $\mathrm{H}_{2} \mathrm{O}_{2}$ concentrations in the range from $4 \mu \mathrm{M}$ to $10 \mathrm{mM}$. Set potential: $-0.75 \mathrm{~V}$ vs. Ag pseudo-reference electrode. Dotted arrows indicate those concentrations for which no current signal could be measured. Solid arrows indicate the lowest concentration for which a current signal could be unambiguously detected with each hybrid. 